definitely lower rate of carbon dioxide evolution. The amounts of solution injected were $0.30 \mathrm{gm}$. in $H$. madablota, $0.43 \mathrm{gm}$. in $A$. tuberosum and $0.36 \mathrm{gm}$. in $O$. Dellenii, and the amounts of water injected in the controls were $0.32 \mathrm{gm} ., 0.38 \mathrm{gm}$., and $0.38 \mathrm{gm}$. respectively per gram of the fresh materials.

Further work is in progress.

$$
\begin{gathered}
\text { Department of Botany, } \\
\text { University of Allahabad, } \\
\text { Allahabad. }
\end{gathered}
$$$$
\text { Jan. } 20 .
$$

${ }^{1}$ J. J. R. Macleod, "Carbohydrate Metabolism and Insulin". Longmans, 1926 .

${ }^{2}$ N. R. Dhar, "New Conceptions in Biochemistry". Indian Drug House, Allahabad, 1932.

\section{Effect of Inoculation of Plant Stems with Bacterium solanacearum}

As experimental study of two primary symptom reactions of tomato and other plants to invasion by the vascular parasite Bacterium solanacearumnamely, petiole-epinasty and adventitious root production-has been made. It has been found that in the tomato epinasty is confined to the lower petioles irrespective of whether the inoculation is made at the top or the bottom of the stem. Growth and bending occur generally in the basal part of the petiole. No epinasty of individual leaflets such as occurs in the case of treatment with ethylene gas has been observed.

A condition for epinasty to occur appears to be that only one lateral petiolar bundle or one lateral bundle and the small central petiolar bundle be invaded. When bacteria invade all three bundle groups of a petiole, wilting occurs without epinasty. The epinasty is permanent and is generally followed by wilting after two to ten days. By means of a new dye, staining and maceration technique, it has been found possible to trace the path of the bacteria in the wood vessels and to explain certain unusual phenomena, such as the failure of one centrally situated petiole in a plant to develop epinasty when others above and below it are reflexed, and the presence of one wilted petiole and leaf among reflexed but otherwise normal petioles and leaves.

Regarding the physiology of the epinastic reaction in tomato, it is considered that the increased growth on the upper side of the petiole is due, in general, to the local action of the bacteria. Although it has been found possible to extract from the bacteria grown in a glucose-peptone medium a physiologically active substance as determined by the Went test ${ }^{1}$, this substance is apparently not produced in sufficient amount in the sap in the invaded vessels to act any distance ahead of the bacteria.

Petiole-epinasty due to $B$. solanacearum has also been demonstrated to occur in potato, African marigold and castor-oil plants. Only the last of these has previously been recorded as showing epinasty as a result of bacterial invasion. Potato shoots are very sensitive and the epinastic reaction is rapid. There is some evidence in the case of the potato and also the other two plants mentioned above, which suggests that the bacteria can cause the reaction from a distance ; but in general here, as in tomato, bacteria are present in one lateral petiolar bundle when epinasty occurs.

With regard to adventitious root formation in tomato, I find, from a detailed histological study of numerous plants, in contrast to Smith $^{2}$ and Hutchinson $^{3}$, that in the majority of cases the bacteria are present in some or all of the wood vessels outside which the roots develop. The formation of adventitious roots in tomato, as a result of infection, is believed to involve causal factors besides that of stimulation. A substance has been obtained from $B$. solanacearum which stimulates active adventitious root formation in tomato and African marigold; but evidence is accumulating to show that in tomato partial blockage of vessels or blockage of a portion of a vascular system also plays an important part. Frequently where complete blockage of vessels by bacteria in a vascular strand running through an internode occurs, no roots develop. This suggests that, in the absence of food supplies, adventitious roots fail to develop even though the root stimulating substance is present in greater concentration. An experimental study of adventitious root formation arising after wounding and after artificial blockage of the vessels with substances such as cocoa fat and gelatin is being carried on in order to throw further light on this point.

The reactions described above are closely similar to those induced by ethylene, carbon monoxide and $\beta$-indolyl-acetic acid as shown by Crocker, Zimmerman and Hitcheock ${ }^{4}$ and Hitcheock ${ }^{5}$.

Botanical Department,

B. J. Grieve.

University,

Melbourne.

Jan. 21.

${ }^{1}$ Went, F. W., Rec. Trav. Bot. neerl., 25, 1 (1928).

${ }^{2}$ Smith, E., "Bacterial Diseases of Plants", p. $199(1920)$

${ }^{3}$ Hutchinson, C., Mem. Dept. Agr. India Bact. Ser., 1, 2 (1913).

- Crocker, Zimmerman and Hitchcock, Contrib. Boyce Thomp. I nst. 4, 177-218 (1932); 5, 1-17 (1933).

${ }^{5}$ Hiteheock, A., Contrib. Boyce Thomp. Inst., 7, 87-95 (1935).

\section{A Chromosomal Basis of Tumours}

IN 1927, Muller showed that X-rays and radium can produce mutational changes. In a continuation of this work on irradiation, I have observed changes in chromosomal number in accordance with findings of other investigators.

It may be mentioned that the cells of tumour tissues usually have an abnormal number of chromo. somes as their peculiar feature. In the autumn of 1935, I applied the salivary gland method to the determination of the chromosome number in tumour tissue. At the same time I conducted experiments with Drosophila melanogaster treated with tar, in order to find out if there are carcinogenous factors, other than X-rays and radium, which can produce mutations.

Of the specimens of Drosophila treated in such s way, twenty-five per cent died. The remainder showed quite normal development. But in the $F_{1}$ and $F_{2}$ generations there was a large decrease in the number of offspring ( 4 and 5 , instead of $100-$ 200 ), and there were changes in the sex ratio in different lines. This may be due to the appearance of a lethal gene.

Quite similar to such an influence in evoking mutational and cancerous changes is the effect of œstrogenic hormones, which is in full accordance with the striking fact that always during the cestrous cycle the meiotic divisions are accompanied by proliferation of the mucosa uteri. This phenomenon can be clearly demonstrated by the statistical dats 